BMJ Open

Diabetes

Research

\& Care

\section{Self-monitoring of blood glucose in insulin-treated diabetes: a multicase study}

To cite: Cameron D, Harris F, Evans JMM. Self-monitoring of blood glucose in insulintreated diabetes: a multicase study. BMJ Open Diab Res Care 2018;6:e000538. doi:10.1136/ bmjdrc-2018-000538

Received 26 March 2018 Revised 24 July 2018 Accepted 13 August 2018
D Check for updates

(c) Author(s) (or their employer(s)) 2018. Re-use permitted under CC BY-NC. No commercial re-use. See rights and permissions. Published by BMJ.

Faculty of Health Sciences and Sport, University of Stirling, Stirling, UK

Correspondence to Dr Josie M M Evans; fiona.harris1@stir.ac.uk

\section{ABSTRACT}

Objective To explore how and why self-monitoring of blood glucose (SMBG) is carried out in a real-world context.

Research design and methods We conducted a multicase study among ten people with type 1 and insulintreated type 2 diabetes mellitus in Scotland, alongside seven nominated support people and four healthcare professionals. All participants were interviewed in depth and six participants provided SMBG diaries. Stones' version of structuration theory informed the analysis. Results People with diabetes were able to provide immediate motives for SMBG at particular times, often having different motives on different occasions. We identified six such motives, including routine, in response to symptoms, associated with a diabetes review, to facilitate lifestyle, when a 'good' result was expected, and higher level motives for longer term glycemic control. These motives were influenced by underlying attitudes toward diabetes that included level of engagement and responsibility for diabetes, a desire not to be controlled by diabetes, resistance to diabetes, diabetes education and relationship with the health service, fear of hypoglycemia, and prevention of diabetes complications. Five responses to test results were identified, depending on the immediate motive and underlying attitudes.

Conclusions People with insulin-treated diabetes do not necessarily self-monitor with an explicit goal of improving long-term glycemic control, but may have other motives that are important to them. An individualized understanding is therefore needed to advise people with diabetes how SMBG can be optimized for them.

\section{INTRODUCTION}

Clinical guidelines recommend regular individualized self-monitoring of blood glucose (SMBG) as a tool for self-management in type 1 diabetes mellitus (four times daily) ${ }^{1}$ and in people with type 2 diabetes who are treated with insulin. ${ }^{2}$ Despite growing evidence on the importance of SMBG as a key component of self-management, many people who are recommended to test routinely are not testing as frequently as recommended, and many are not testing at all. ${ }^{3}$ There is also wide variation in individual practice of SMBG: frequency, timing, the measurement itself, interpretation of readings, resulting actions taken, and

\section{Significance of this study}

What is already known about this subject?

- Despite growing evidence on the importance of self-monitoring of blood glucose (SMBG) as a key component of diabetes self-management, there is wide variation in individual SMBG practice, with the clinical benefits identified from experimental studies often not replicated in observational studies.

What are the new findings?

- This multicase study has established that people with insulin-treated diabetes are able to provide immediate motives for why they self-monitor their blood glucose at particular times, with the same person often having different motives on different occasions.

- The motives are strongly influenced by underlying attitudes toward diabetes, with motive and attitudes influencing the action taken in response to the test result.

How might these results change the focus of research or clinical practice?

- It is important to have individualized understanding of SMBG in a real-world context in order to advise people with diabetes as to how SMBG can be optimized for them.

evaluation of the outcome. ${ }^{4}$ These wide variations in practice may account for why clinical benefits identified from experimental studies that require SMBG to be undertaken according to strict protocols are often not replicated in observational studies. ${ }^{5}$ For this reason, it is important that individual self-management in diabetes is studied in a real-world context. ${ }^{6}$ We have conducted a multicase study among insulin-treated people with type 1 and type 2 diabetes mellitus in Scotland to explore in depth how and why they carry out SMBG within the context of their daily lives.

\section{RESEARCH DESIGN AND METHODS}

This study used a multicase study approach ${ }^{7}$ to explore processes and behaviors around SMBG among people with diabetes in 
Scotland. Each case comprised an individual with type 1 or insulin-treated 2 diabetes mellitus (the patient participant), along with a support person and/or a healthcare professional (HCP). The data were supplemented with blood glucose monitoring diaries for six patient participants.

People with diabetes were recruited from diabetic outpatient services within an NHS Health Board in Scotland, UK. Sixteen eligible people were identified and consented by their clinician to consent to speak with the researcher (DC) who provided a face-to-face overview of the study. The eligibility criteria specified that individuals be over the age of 18 years, have type 1 or insulin-treated type 2 diabetes mellitus, were English-speaking and had the capacity to consent. A convenience sampling technique was used iteratively to ensure that recruitment continued until the sample captured sufficient diversity in terms of age, sex, diabetes type and duration, and socioeconomic status. Potential participants were then asked to complete a 'consent to contact' form with their contact details and to identify a key support person: this could be a friend, relative, or work colleague; or an individual who supported them in some way with their diabetes. They also identified a key HCP who assisted with their diabetes management: this could be their diabetes consultant, diabetes specialist nurse, dietitian, practice nurse, general practitioner, or podiatrist. They were given 'consent to contact' forms to pass on to these individuals. The researcher proceeded to recruit and take informed consent from all individuals who provided contact details.

The final sample consisted of 10 cases (21 individuals). Ten patient participants agreed to take part, along with seven support people, and four HCPs identified by four patient participants. One patient participant was unable to identify a support person, and two support people did not return their consent to be contacted. Six HCPs did not return consent. This was a relatively large sample size for a case study, with detailed information from several sources available for each case.

Prior to fieldwork commencing among these participants, two pilot telephone interviews were carried out with the support people of patients with diabetes (one mother, one daughter-in-law), and three people with diabetes were asked to complete patient diaries. Indepth, semistructured, face-to-face interviews were then undertaken with each of the patient participants by DC. Seven of these interviews were undertaken in the participant's home and three on university premises; all were audio-recorded, with only the participant and the interviewer present, and lasted around 1 hour. Participants were then provided with a diary to complete with the details of all SMBG that they undertook over any 2-week period. Telephone interviews were carried out with the HCPs and support people and lasted between 30 and 45 min. Interviews were audio-recorded and transcribed verbatim. Question guides were used during all interviews, but the semistructured nature allowed the interviewer to explore emerging areas of interest during the process. Finally, one HCP (a diabetes consultant) was asked to read and comment on all patient diaries.

All recruitment and fieldwork were carried out by DC, who had no previous contact with any of the participants. Field notes were made during the recruitment and interview processes. DC has a background in primary care practice and community nursing, which involved general diabetes management and the management of diabetes clinics. The participants were made aware of her background in the Participant Information Sheet, and this understanding facilitated effective communication between them, encouraging indepth conversation and exploration of the topic. However, DC took care to avoid making clinical assumptions based on previous experience, and she had no access to hemoglobin A1c (HbA1c) results or other clinical data of participants.

An interpretive approach to analysis was facilitated by use of QSR NVivo (V.11) software for first stage coding of the data. A constant comparative method was applied, ${ }^{8}$ commencing with open coding, leading to the development of conceptual categories. Stones' structuration theory was used to guide the theory generation stage of analysis. ${ }^{9}$ Structuration theory posits that individual decision making and actions are dependent on a person's nature and capabilities, which in turn are affected by wider structures. Informed by this theory, we mapped the analytical concepts on to underlying attitudes and beliefs and how these influenced immediate motives for testing, as well as how they affected subsequent actions and responses to test results. Thus we created a conceptual model for SMBG practice. Variations in views were considered and data re-examined to identify and explain disconfirming evidence. An epidemiologist (JMME) and a medical anthropologist (FH) helped to ensure that wider perspectives informed the analysis.

\section{RESULTS}

The characteristics of the ten cases (ten patient participants with seven support people, four HCPs and six diaries) are presented in table 1 . All names are pseudonyms.

Data from the pilot interviews and diaries were also used in the final analysis where it was felt that they contributed to interpretation. Initial analysis revealed varying explanations for why and how people with diabetes self-monitor their blood glucose. Participants were able to provide immediate reasons (which we have defined as immediate motives) for why they self-monitored at particular times, with the same participant often having different immediate motives on different occasions.

For all but one participant, SMBG was carried out routinely, forming part of everyday practice, for at least some of the time.

I take it [blood glucose reading] as soon as I get up in the morning before I do anything. (Angus) 


\begin{tabular}{|c|c|c|c|c|c|c|c|c|}
\hline $\begin{array}{l}\text { Case: } \\
\text { participant } \\
\text { pseudonym }\end{array}$ & $\begin{array}{l}\text { Age } \\
\text { (years) }\end{array}$ & $\begin{array}{l}\text { Diabetes } \\
\text { mellitus } \\
\text { type }\end{array}$ & $\begin{array}{l}\text { Diabetes } \\
\text { mellitus } \\
\text { duration } \\
\text { (years) }\end{array}$ & Occupation & Living situation & $\begin{array}{l}\text { Support } \\
\text { person }\end{array}$ & $\begin{array}{l}\text { Healthcare } \\
\text { professional } \\
\text { pseudonym }\end{array}$ & Diary \\
\hline Michelle & $<20$ & 1 & $5-10$ & Student & Alone & Mother & - & \\
\hline Maureen & $45-50$ & 1 & $>20$ & Housewife & $\begin{array}{l}\text { With spouse/ } \\
\text { children }\end{array}$ & Spouse & Dr Hay & \\
\hline Angus & $70-75$ & 1 & $15-20$ & Retired professional & With spouse & Spouse & - & $\sqrt{ }$ \\
\hline Tam & $65-70$ & 2 & $5-10$ & $\begin{array}{l}\text { Unemployed } \\
\text { pensioner }\end{array}$ & With partner & Partner & - & $\sqrt{ }$ \\
\hline Brian & $65-70$ & 1 & $>20$ & $\begin{array}{l}\text { Retired non- } \\
\text { professional }\end{array}$ & Alone & Partner & $\begin{array}{l}\text { Podiatrist } \\
\text { Colin }\end{array}$ & $\sqrt{ }$ \\
\hline Pauline & $55-60$ & 1 & $<5$ & $\begin{array}{l}\text { Healthcare } \\
\text { professional }\end{array}$ & Alone & - & Dr Whitby & $\sqrt{ }$ \\
\hline Alison & $45-50$ & 1 & $>20$ & $\begin{array}{l}\text { Healthcare } \\
\text { professional }\end{array}$ & With spouse & Friend & Dietitian Sally & $\sqrt{ }$ \\
\hline Bill & $70-75$ & 2 & $>20$ & $\begin{array}{l}\text { Retired non- } \\
\text { professional }\end{array}$ & With partner & Partner & - & \\
\hline Peter & $60-65$ & 2 & $15-20$ & Retired professional & Alone & - & - & \\
\hline Charles & $60-65$ & 2 & $5-10$ & Retired professional & Alone & - & - & $\sqrt{ }$ \\
\hline
\end{tabular}

Routine testing generally involved testing at certain points in the day and/or at mealtimes, usually at home. Interestingly, the only participant who did not routinely monitor considered HbAlc to be the more important marker of glycemic control.

I mean the key measure is always HbAlc, that's the target, I've always been encouraged to consider it the target variable. (Charles)

The routine nature of testing was noted to be ingrained and built on past experiences, with the impression that some participants would not consider changing practices they had undertaken for many years.

Aye this guy's an old hand you see, he's been type 1 for 45 years and he's fairly set in his ways. (Podiatrist Colin)

The entire range of responses was observed for routine SMBG, from no action to higher level analytical responses (table 2).

For many participants, there was a notable change in behavior around SMBG and associated self-management prior to, or following, a diabetes review or clinic appointment. These changes included initiation of testing after a period of non-testing, an increase in testing frequency, or payment of more attention to testing, evidenced through documenting results and subsequent responses. In general, the responses were either lacking, or reactive and short term. Michelle stated explicitly that this was an important motive for testing:

Yes, yes ... (giggle) ... Yeah so maybe in the week running up to an appointment, I probably do more testing than I should be because I'm trying to almost work harder to have these where they should be so they are not seeing results way down at the bottom or way up at the top, so, I just pray they don't go too far enough back to see the other ones ... (giggle) ... (Michelle)

Indeed, all four HCPs were aware that SMBG behaviors could sometimes be directly linked to clinic visits and perhaps a desire by people to show that they were 'good patients'.

Maybe the two weeks prior to their visit to the clinic may be different to normality ... well, yes ... so in the patient's view, they will be 'behaving themselves', ... but I think sometimes the patient will behave differently if they know that an appointment is imminent and they are starting to check where they wouldn't have checked particularly before. (Podiatrist Colin)

Some participants tested when they thought that their result would be at the required level: "almost when it's, it's fine" (as a mother of a young person with diabetes commented in pilot data). There would be no action in response. A fear of seeing high blood sugar results, and also not wanting or having the time to act on these, was an important factor in this, as one HCP explained; people may well avoid testing when they suspect that results will be outwith the desired range.

There are other patients who will avoid monitoring at times when they know that it's going to be an abnormal result, because they don't want to deal with it. (Dr Whitby)

Given the difficulties people have regarding the juggling of work and family commitments, being prepared for "abnormal" results and allowing time to respond to them influenced testing and timing of the test. 
Table 2 Summary of actions/responses to self-monitoring of blood glucose (SMBG) reported to have been carried out for each immediate motive for monitoring

\begin{tabular}{ll}
\hline Immediate motive & $\begin{array}{l}\text { Actions/responses } \\
\text { reported }\end{array}$ \\
\hline Routine & $\begin{array}{l}\text { Full range of actions/ } \\
\text { responses }\end{array}$ \\
$\begin{array}{l}\text { Prior to, or following, a } \\
\text { diabetes review or clinic } \\
\text { appointment }\end{array}$ & $\begin{array}{l}\text { No action, reactive actions, } \\
\text { short-term actions }\end{array}$ \\
$\begin{array}{l}\text { Know result will be at good/ } \\
\text { stable level }\end{array}$ & No action \\
$\begin{array}{l}\text { To facilitate everyday lifestyle } \\
\text { activities }\end{array}$ & $\begin{array}{l}\text { Short-term actions, longer } \\
\text { term actions }\end{array}$ \\
$\begin{array}{l}\text { In response to physical } \\
\text { symptoms }\end{array}$ & $\begin{array}{l}\text { Full range of actions/ } \\
\text { responses }\end{array}$ \\
Higher level analytical & Higher level analytical \\
motives & responses \\
\hline
\end{tabular}

Key to actions/responses:

No action: result might be documented but no further action taken.

Reactive actions: immediate action taken involving little thought, usually glucose/carbohydrate intake or the administration of insulin.

Short-term actions: some thought given to SMBG result and the required response; for example, carbohydrate intake or insulin taken with consideration of future energy expenditure. Long-term actions: consideration of the type and level of action taken, rechecking the effect of actions, and consideration of future carbohydrate intake and energy expenditure over the rest of the day and possibly into the next.

Higher level analytical responses: movement beyond long-term thinking to questioning why blood glucose levels move to the levels they do, looking at results together in the context of life and lifestyle, and analyzing this over several days.

It gives you an answer maybe that you don't want, because actually you don't want to know that you're less than 5, when you know you've got to pick your child up from gymnastics in $10 \mathrm{~min}$, because you can't, you've got to do something about your diabetes first (laugh). (Dietitian Sally)

A fourth important immediate motive for SMBG was to facilitate everyday lifestyle activities, specifically to enable driving (underpinned by legislative requirements) or to allow participants leeway to consume the food and drink (including alcohol) that they wished (which might involve accepting blood glucose levels at higher than recommended limits). Associated responses could be short or longer term. Driving was specifically mentioned by seven of the ten participants with diabetes, and HCPs also recognized that driving was a strong motive.

Just because it's so much easier to control your life ... I have to do it before eating and before driving, so it has to be over 5 to drive, and because I do drive quite a lot obviously for work, I'm taking mine a bit more than the average person is. (Pauline)
Tam, Brian, Pauline and Michelle all referred to SMBG as affording them the confidence to consume food and drink that are not part of recommended diabetes dietary plans, and Charles explicitly gave as a reason for testing: "if I fancy a dessert or something."

All participants referred to testing in response to physical symptoms, mostly those associated with low blood glucose. These symptoms were reported to be more noticeable and unpleasant than those of high blood glucose. The entire range of responses was observed in relation to this immediate motive.

Eh ... no so much when you go high like, it's more when you are going doon to 2 or 3 , you can actually feel it ... within yourself ... I've never had anything when it goes high, I've never felt oot of sync or that when it's high ... but in the mornings when it's low ... you can feel it, but as I've said, it's gone up to 30, I don't feel any different. (Tam)

Finally, higher level analytical motives, such as the desire to control blood glucose levels over a longer period and even to reduce risks associated with poor diabetes control, were evident for a minority of participants. These motives initiated responses whereby the individual engaged in problem-solving, forward or longer term planning and analytical thinking, and were observed to differing levels by Alison, Maureen and Bill. They followed up on actions, whereby they would test again following an action taken in order to check its effect on blood glucose levels.

Already I'm thinking, well if it says, whatever the result is, well I'm having that for tea, so therefore what'll mean, em or I'll go and do, I'm going away out and/or exercising, so if it's that, then I'm eating that and I need to cut back on the insulin because of that later. (Alison)

The immediate motives for testing are listed in table 2 . There were also different actions/responses made to testing. These were categorized as no action, reactive action, short-term action, longer term action, and higher level analytical responses. They are defined in table 2, and the different actions/responses reported by participants are listed for each motive.

On further analysis, it became clear that there were several prominent beliefs and attitudes surrounding diabetes that were held to varying degrees by different participants with diabetes. These appeared to underpin the immediate motives for SMBG and subsequent responses. Figure 1 shows how these concepts fit into the theoretical model. The underlying attitudes held by people with diabetes toward SMBG are part of their 'internal structures', that is, what they know and their general and specific understandings, which influence the 'actions' that they take. The actions can be viewed as both the SMBG process itself and the responses to the test result. The immediate motive for SMBG can be viewed as another mediating layer. 


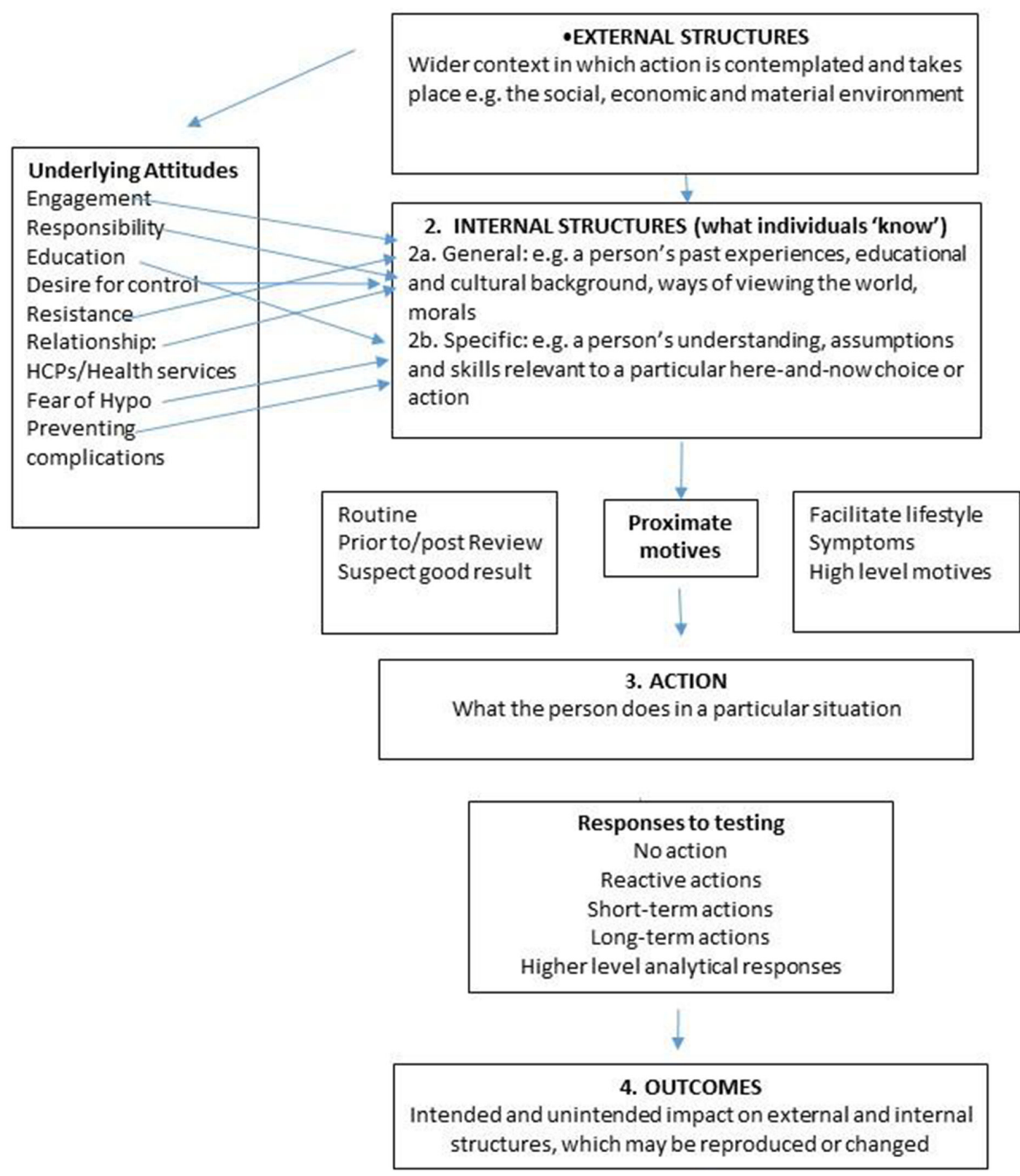

Figure 1 How concepts fit into the theoretical model. HCP, healthcare professional.

\section{Level of engagement}

A very important underlying attitude was level of engagement with diabetes. At one end of the spectrum, one participant (Tam) was sometimes so disengaged with his diabetes on a day-to-day basis that he often ate what he liked and could forget to inject insulin.

... but there is ... you do forget sometimes ... I even

forget sometimes to inject myself. (Tam)

The most common and sometimes the only observed immediate motive for disengaged participants was routine SMBG that involved little thought. In contrast, another participant (Alison) was fully engaged with her diabetes and referred to it as "part of me." She was one of the few participants who exhibited higher level motives for SMBG.

\section{Responsibility}

The extent to which the participant felt it was their responsibility to manage their diabetes was linked to level of engagement. Alison explicitly stated that she felt responsible, as did Brian, while Bill spoke about a lack of responsibility in others. By definition, those who tested to facilitate their lifestyle were showing some degree of responsibility (although this could be relatively short term), while participants with higher level motives exhibited high levels of responsibility.

It's my body, right, with eh, the tools and the information that I've got already, then it's up to me to manage my body and that's what I'm trying to do. (Brian)

Ignoring it, it's stupid, I know folk that do that. (Bill)

\section{Diabetes education}

Engagement and responsibility were facilitated by diabetes education, but it was evident that there were different levels of desire, need and access to education, or indeed to understand diabetes.

There's good quality education out there, some want it, some don't and as I say some don't have access to the things they want. (Dietitian Sally) 
Level of diabetes education was associated with the immediate motive for testing. A certain level of education is necessary for longer term planning and thus 'higher-level motives', while routine SMBG was observed particularly among those whose knowledge was limited or more outdated, not necessarily through any fault of their own. This was recognized by HCPs.

Patients with longstanding diabetes were educated at a time when insulin dose adjustment wasn't something we recommended and we tended to dictate what the solutions were rather than encouraging patients to selfmanage which is what we do now. (Dr Whitby's comments on diary extracts)

\section{Desire for control}

The desire for control was an underlying theme: the desire of participants to control diabetes, rather than be controlled by it, and to manage or to reclaim their lives, that is, have a good quality of life and not let diabetes take over. For example, Pauline felt she was able to and wanted to manage her life without "dwelling" on diabetes. There was a real focus on how SMBG worked to allow her to manage her life as she would without diabetes, rather than as a tool to manage diabetes effectively.

... but it's great just getting on with life (laugh) and not worrying about it too much .... I don't dwell on it, I just get on with it. (Pauline)

Maureen, on the other hand, recognized that when she lost control, it affected her confidence and self-efficacy. She elaborated: "the last year, I've been having lots of problems due to my diabetes, so I don't feel as confident as I did before."

Facilitating everyday activities through SMBG was one way in which participants could manage their own lives, as Pauline explained: "It's so much easier to control your life, because you have the choice ... your life's not different, well you know what I mean."

However, this study also revealed that people with diabetes acknowledge behaviors and subsequent readings that would not be advocated by HCPs, and that this can be driven by a desire for 'normality', making informed decisions to do something enjoyable in the knowledge that this might not necessarily lead to optimal self-management. At least three participants referred to experiencing high blood glucose levels as a result of their chosen behaviors. Brian's diary provides a somewhat humorous illustration of this tendency.

Day 2: Before evening meal $=14.2 \ldots$ this is ok after 2 pints of beer, most enjoyable. Day 3: Before evening meal=16.4 ... that's ok after 4 pints of beer, well it is Saturday ... I can live with it ... let's see what happens tomorrow. (Brian's diary extract)

Brian explained, "I'm not saying I'm managing it perfectly, but I'm managing it to my satisfaction ... and I'm happy with that ... if you can understand that."

It is important that HCPs are aware of the trade-offs that people with diabetes feel they need to make, as podiatrist Colin explains about Tam, and Dr Whitby indicates in her comments on Brian's diary extract:

He quite simply doesn't want to change, he's happy with the way his diabetes is controlled, eh, he's happy with the way he can function ... it's his habit to socialize with his friends at the pub between 4 and 6pm (laugh), he doesn't want anything to distract from his quality of life. (Podiatrist Colin)

He sees his actions as common sense actions again a feature of long-standing diabetes, many habits and beliefs are ingrained ... if he cannot continue with his ritual of a couple of pints, he will lose control. (Dr Whitby)

\section{Resistance}

Some participants with diabetes resisted 'interference' in their diabetes, which seemed to be linked to their efforts to retain control over their lives and their condition. Resistance was played out in several ways: resistance to HCPs and their advice, resistance to support persons, or resistance to the condition itself.

Brian provided an example of someone who resisted hospital-based control in an effort to reclaim 'normality':

I suppose that's my little bit of rebellion; like wanting to be normal (laugh) ... and there's nothing they [hospital clinic doctors] can do about it (laugh). (Brian)

On the other hand support people explained their early experiences with providing support to their children, which could initiate angry outbursts or resentment.

I had to get a grip and kind of step back because you know I think she got so fed up with me continually asking her if she's taken her Lantus [long acting insulin] or done this or done that, you know (pilot data) the more I ask the more she gets angry. (Michelle's mother)

Resistance was also observed toward the condition itself, partly from a wish not to be identified by it, as exemplified by Tam.

I mean, I know couple of people that are diabetic and I dinnae go and talk aboot it with them, you know it's not really eh, I don't think it would benefit me. (Tam)

Similarly, Michelle's mother believed that Michelle does not engage with her diabetes "because of this whole thing of not wanting to identify with her diabetes ... or ... you know."

Resistance and denial were associated with routine testing without acting on the blood glucose results, and also testing before a clinic appointment or when the participant knew the result would be good.

\section{Relationship with the health service and HCPS}

The hierarchical or paternalistic model of care was perceived by some participants to be the dominant one, along with a desire to be regarded as 'compliant', doing what they were told to do and gaining approval from HCPs (whether or not they were actually compliant in practice). This attitude was particularly evident with Tam: 
Cause they were'na happy with me when I was in the last time ... eh they were'na happy with me then. (Tam)

Michelle's non-collaborative relationship with HCPs, described by her mother, was related to her impression of SMBG as a "test" where she was being assessed or felt she was being judged. This is apparent from some of the terminology that she used (eg, "scores").

She goes in she gets out again as quickly as she can ... it's not a collaborative experience, it's not a supportive experience. (Michelle's mother)

You had to write down all your scores and they went round the room, which was 'ah no!'... (Michelle)

The main immediate motives for SMBG for such participants were when a clinic appointment was coming up or when they knew the result would be good. In contrast, other participants reported an effective and collaborative relationship with their HCPs (and thus a more concordant model of care). These were the participants who were more likely to report higher level motives for testing.

... they will say ... you are doing really well, you are doing what you can do with the tools you have. (Alison)

\section{Fear of hypoglycemia}

Fear of hypoglycemia was dominant among participants with diabetes and was the main driver for testing in response to physical symptoms.

It scares the shit out of me ... I don't want to have another hypo, right, I don't want to! (Brian)

This fear was recognized by Dr Whitby who explained it thus:

People have a fear of hypos because of the neurological symptoms, risk of unconsciousness and the need for third party help if it's severe ... I think it is easier to ignore something that doesn't have an immediate adverse outcome like a hypo. (Dr Whitby)

In general, participants were much less concerned or cognizant of symptoms relating to high blood glucose levels, with Tam, for example, "more frightened about it going doon ... than going high."

\section{Prevention of long-term complications}

That SMBG was carried out in order to achieve good diabetic control for the prevention of long-term complications was explicitly articulated, to a varying extent, by only three participants with diabetes. This recognition was required for them to exhibit higher level motives for testing. There was a clear awareness among them of goals or targets in relation to SMBG, in contrast to viewing goals as a notion referred to during consultation with HCPs but not something that is achievable in reality.

\section{DISCUSSION}

This study indicates that SMBG is not a stand-alone process but takes place within a complex set of external and internal structures. It has been argued that failure to find evidence for an association between SMBG and improved glycemic control relates to factors such as lack of understanding of what the measurements mean, how they should be used, and how individuals might make changes to insulin dose and other practices. ${ }^{10}$ However, we have shown that it seems to be relatively uncommon for people to test with a view to improving long-term glycemic control. In fact, many have other motives for testing: as a matter of routine, to facilitate everyday activities, to demonstrate adherence, and to impress HCPs (and themselves) when results are 'good'. These motives seem to be related to underlying attitudes (internal structures) surrounding diabetes itself.

Several qualitative studies have identified other constructs that have implications for diabetes self-care in general. ${ }^{11}$ These include level of engagement, resistance to a diabetic identity, different degrees of personal responsibility and the challenges of trying to retain a 'normal' life. We have shown that they also affect whether and how SMBG is carried out. Self-management practices may also change and develop over time. ${ }^{11}$ There have been calls for educational interventions to improve knowledge and understanding surrounding SMBG in terms of how to carry out SMBG operationally. There have also been calls for educational interventions relating to interpretation of results. ${ }^{12}$ Others have recognized the importance of addressing motivation and behavior change. ${ }^{13}$ However, we have shown that the barriers to effective SMBG may be much more fundamental than this. The diabetes-related attitudes and beliefs that individuals hold (internal structures) have direct implications for SMBG practices and associated responses.

The nature of the relationship between the individual and the health service is also of paramount importance. This is recognized by Diabetes UK, who stress that HCPs should work in partnership with people with diabetes on a patient-by-patient basis to decide jointly on testing frequency. ${ }^{14}$ However, very few patient participants in our study appeared to work collaboratively with their HCPs. This lack of collaboration in diabetes care has been highlighted elsewhere, with doctor-centered consultation styles driving the 'compliance' model of communication rather than the 'concordant' approach that is assumed to be the norm. ${ }^{15}$ While it has been argued that diminishing trust in healthcare by the public also poses challenges to the concordant (or collaborative) model ${ }^{16}$ a lack of trust did not appear to be at the root of less than optimal SMBG practices and behaviors among our patient participants, but rather there was a disconnect between the ideal medical model of diabetes care and what mattered to them, with some of them willing to compromise optimum diabetes care and future health in order to lead the lifestyle that was important to them.

This study has thus shown that there needs to be a move away from a prescriptive approach to SMBG where 'one size fits all', and an attempt to understand individuals in the context of their own lives, the internal beliefs that they hold and the external structures surrounding them. 
By using structuration theory to inform the design and analysis, we have highlighted the importance of internal structures in the SMBG process (people's experiences, backgrounds, viewpoints, skills and knowledge). These are represented in underlying attitudes toward diabetes. They are also influenced by the external social, economic and material environment. For example, while provision of diabetes education and relationship with HCPs are a direct product of the external environment, other attitudes and motives (eg, desire to have a certain lifestyle or to drive) are influenced by social and material circumstances.

Important strengths of this study include the recruitment of a diverse set of cases, with detailed information collected for each one from several sources. There were six patient participants with type 1 diabetes and six with type 1 diabetes, including some recently diagnosed and some with diabetes for over 20 years. There was also a wide age range (although we were unable to recruit any patient participant in the age group 20-45 years old). However, although the sample size was ample for a case study, the study was undertaken in a single Scottish Health Board. It was not possible to obtain a full set of data for all ten cases (two participants were unable to identify a support person and not all completed diaries) and no HCPs were recruited from general practice. While we ensured that a selection of transcripts were coded independently by all three authors and the framework was developed through discussion between them to allow for varied and richer interpretations of the data, it is still possible that this study was influenced by individual researchers' backgrounds and beliefs. Nevertheless, this study has highlighted the importance of taking into account the real-world context for individuals when they practice SMBG and self-management, if we wish to understand and support effective self-management behavior. This may involve HCPs taking a more collaborative and realistic approach, involving shared decisions about self-management, and the setting of achievable goals that are mindful of patients' wants and needs in the context of their everyday lives.

Acknowledgements We would like to acknowledge the assistance of staff who identified potential patient participants from outpatient clinics. We would like to thank all participants for taking part.

Contributors DC, FH and JMME designed the project. DC conducted all recruitment and fieldwork, and carried out qualitative analysis. FH supervised the qualitative analysis, and JMME contributed to analysis. DC wrote the first draft of the paper. JMME edited the first draft and was responsible for the final draft. All three authors approved the final version. JMME is the guarantor.
Funding This study was undertaken within a PhD studentship that was partfunded by Lifescan, Inverness. The researchers were independent of the funding body.

Competing interests None declared.

Patient consent Not required.

Ethics approval Ethical approval for this study was obtained from the Research Ethics Committee of the School of Health Sciences, University of Stirling, and from the East of Scotland NHS Research Ethics Service (13/ES/0119).

Provenance and peer review Not commissioned; externally peer reviewed.

Data sharing statement There are no additional data available from this study.

Open access This is an open access article distributed in accordance with the Creative Commons Attribution Non Commercial (CC BY-NC 4.0) license, which permits others to distribute, remix, adapt, build upon this work non-commercially, and license their derivative works on different terms, provided the original work is properly cited, appropriate credit is given, any changes made indicated, and the use is non-commercial. See: http://creativecommons.org/licenses/by-nc/4.0/

\section{REFERENCES}

1. National Institute for Health and Clinical Excellence. Type 1 diabetes in adults: diagnosis and management. NICE Guideline 17. London: National Institute for Health and Clinical Excellence, 2015.

2. IDF Clinical Guidelines Task Force. 2012.Global Guideline for Type 2 Diabetes https://www.idf.org/e-library/guidelines/79-globalguideline-for-type-2-diabetes.html (accessed 13 Nov 2017).

3. Cameron D, Harris FM, Evans JM. Patterns of self-monitoring of blood glucose in insulin-treated diabetes: analysis of a Scottish population over time. Diabetes Obes Metab 2016;18:729-31.

4. Hortensius J, Kars MC, Wierenga WS, et al. Perspectives of patients with type 1 or insulin-treated type 2 diabetes on self-monitoring of blood glucose: a qualitative study. BMC Public Health 2012;12:167.

5. McAndrew L, Schneider SH, Burns E, et al. Does patient blood glucose monitoring improve diabetes control? A systematic review of the literature. Diabetes Educ 2007;33:991-1011.

6. Hinder S, Greenhalgh T. "This does my head in". Ethnographic study of self-management by people with diabetes. BMC Health Serv Res 2012;12:83.

7. Yin RK. Case study research: design and methods. 3rd edn. London: Sage, 2003.

8. Strauss A, Corbin J. Basics of qualitative research: grounded theory procedures and techniques. London: Sage, 1990.

9. Stones R. Structuration theory: traditions in social theory. Basingstoke: Palgrave MacMillan, 2005.

10. Heller SR. Self-monitoring of blood glucose: a promise still unfulfilled? Diabetologia 2014;57:847-9.

11. Audulv $\AA$. The over time development of chronic illness selfmanagement patterns: a longitudinal qualitative study. BMC Public Health 2013;13:452.

12. Austin MM. The two skill sets of self-monitoring of blood glucose education: the operational and the interpretive. Diabetes Spectrum 2013;26:83-90.

13. Fisher WA, Kohut $\mathrm{T}$, Schachner $\mathrm{H}$, et al. Understanding selfmonitoring of blood glucose among individuals with Type 1 and Type 2 diabetes. Diabetes Educ 2011;37:85-94.

14. Diabetes UK. Position Statement. Self-monitoring of blood glucose for adults with type 1 diabetes. London: Diabetes UK, 2017.

15. Bissell P, May CR, Noyce PR. From compliance to concordance: barriers to accomplishing a re-framed model of health care interactions. Soc Sci Med 2004;58:851-62.

16. Stevenson F, Scambler $\mathrm{G}$. The relationship between medicine and the public: the challenge of concordance. Health 2005;9:5-21. 